University of Nebraska - Lincoln

DigitalCommons@University of Nebraska - Lincoln

1984

\title{
Partitioning Solar Radiation into Direct and Diffuse, Visible and Near-Infrared Components
}

\author{
A. Weiss \\ University of Nebraska - Lincoln
}

Follow this and additional works at: https://digitalcommons.unl.edu/natrespapers

Part of the Natural Resources and Conservation Commons, Natural Resources Management and Policy Commons, and the Other Environmental Sciences Commons

Weiss, A., "Partitioning Solar Radiation into Direct and Diffuse, Visible and Near-Infrared Components" (1984). Papers in Natural Resources. 1183.

https://digitalcommons.unl.edu/natrespapers/1183

This Article is brought to you for free and open access by the Natural Resources, School of at DigitalCommons@University of Nebraska - Lincoln. It has been accepted for inclusion in Papers in Natural Resources by an authorized administrator of DigitalCommons@University of Nebraska - Lincoln. 


\title{
PARTITIONING SOLAR RADIATION INTO DIRECT AND DIFFUSE, VISIBLE AND NEAR-INFRARED COMPONENTS*
}

\author{
A. WEISS and J.M. NORMAN
}

University of Nebraska, Panhandle Research and Extension Center, Scottsbluff, NE 69361 (U.S.A.), Agronomy Dept., University of Nebraska, Lincoln, NE 68583 (U.S.A.)

(Received March 19, 1984; revision accepted November 6, 1984)

\begin{abstract}
Weiss, A. and Norman, J.M., 1985. Partitioning solar radiation into direct and diffuse, visible and near-infrared components. Agric. For. Meteorol., 34: 205-213

Measurements of total and diffuse, solar and visible (photosynthetically active, PAR) irradiance were made during portions of the summer months of 1979,1980 , and 1981 near Scottsbluff, NE. The objective of this experiment was to obtain equations to predict direct beam and diffuse irradiance in both the visible (PAR) and near-infrared wave bands from measurements of only the total incoming solar radiation. Relationships for potential values of direct and diffuse, visible and near-infrared radiation were established from "clear day" experimental data. Estimates of total visible (PAR) and near-infrared radiation were made by partitioning the measurement of solar radiation using estimates of potential visible and potential near-infrared radiation. Estimates of direct components in the visible and near-infrared were made with relationships developed from the experimental data. There was good agreement between predicted and measured values of the various components of solar radiation. In addition, a correction term for the measurement of diffuse solar radiation with a silicon cell pyranometer was developed.
\end{abstract}

\section{INTRODUCTION}

There are many models available for the prediction of all or various parts of the incoming solar spectrum (Davies and Idso, 1979; Brock, 1981; Dave, 1981; Ideriah, 1981; Munro and Young, 1982). Studies on the utilization of solar energy require the division of the direct beam and diffuse radiation from the total solar irradiance, e.g., Erbs et al. (1982). The complexity of each model is a function of the application of the output data with its associated requirements of accuracy.

Solar radiation submodels for use in deterministic plant growth simulations (e.g. Norman, 1979) must consider the visible $(400-700 \mathrm{~nm})$ or photosynthetically active radiation (PAR) and the near-infrared (NIR, 700$3000 \mathrm{~nm}$ ) portions of the solar spectrum separately. The visible (PAR) portion of the solar spectrum is necessary to determine photosynthesis and stomatal conductance, while the total spectrum is required for energy

\footnotetext{
* Published as paper No. 7441, Journal Series, Nebraska Agricultural Experiment Station.
} 
balance calculations of canopy temperature or water use. Furthermore, the leaf spectral properties in the PAR and NIR wave bands are so drastically different that any reasonable analysis of plant canopy radiative transfer requires their separation (Gausman and Allen, 1973). A futher requirement of plant canopy radiative transfer models is the partitioning of the solar spectrum into direct beam and diffuse components for both PAR and NIR wave bands. This distinction is necessary as the penetration of direct beam and diffuse radiation into the canopy is very different. For example, a canopy with a leaf area index (leaf area per unit ground area) of two might typically have a diffuse transmittance of $25 \%$, while the direct beam transmittance may vary from near zero to $40 \%$ or more, depending on solar zenith angle. Futhermore, those leaves exposed to the direct solar beam, whatever level of the canopy they might be in, will be exposed to flux densities varying from a few percent of full sunlight (leaves parallel to the solar beam) to that of full sunlight on a surface normal to the sun (leaves facing the sun). Combining this variability in canopy radiation environment with the highly non-linear dependence of photosynthesis and stomatal conductance on light, provides a compelling reason for obtaining direct and diffuse PAR and NIR above the canopy. Failure to differentiate between direct beam and diffuse radiation within the canopy can lead to erroneous calculations of photosynthesis (Norman, 1980), because diffuse radiation is used much more efficiently than direct radiation by a canopy of photosynthesizing leaves.

The radiation submodel should not be excessively long, and its accuracy should be of the same order of magnitude as the other submodels that comprise the overall model. Input data to run such a submodel should be easily available. Such data as date, time, latitude, longitude, and hourly values of total integrated solar radiation are needed. Data on total solar radiation meet these criteria because of the availability of low-cost silicon cell pyranometers combined with networks of automated weather stations that routinely supply hourly values of this and other meteorological parameters (Hubbard et al., 1983).

The object of this paper is to describe a series of radiation measurements and the resulting relationships that allow for the prediction of direct and diffuse, visible (PAR) and near-infrared (NIR) radiation.

\section{MATERIAL AND METHODS}

The data for this experiment were collected at the Agricultural Meteorology Laboratory of the University of Nebraska, Panhandle Station $\left(41^{\circ} 57^{\prime}\right.$ $\mathrm{N} 103^{\circ} 41^{\prime} \mathrm{W} ; 1225 \mathrm{~m}$ above m.s.l.) located about $9 \mathrm{~km}$ northwest of Scottsbluff, Nebraska. The following sensors were used: an Eppley precision spectral pyranometer measured total incoming solar radiation, an Eppley Black and White pyranometer measured diffuse solar radiation, two LI-COR silicon cell pyranometers also measured total and diffuse solar components, 
and two LI-COR flat response photosynthetic irradiance sensors (LE-200) measured total incoming and diffuse visible (PAR) radiation. Shadow bands built on the design of Horowitz (1969) were used to measure the diffuse components. The influence of the shadow band in blocking a portion of the sky was compensated by multiplying the diffuse measurements by 1.15 , recommended by Drummond (1964) for isotropic skies. This correction factor of 1.15 is an underestimate for mostly clear skies when the diffuse radiation is small, and a good estimate under mostly cloudy and overcast conditions when the diffuse radiation is large.

The signals from the sensors were recorded on digital integrators (Campbell Scientific, Logan, Utah) and hourly averages of the six quantities were recorded on cassette tape for later analysis. Measurements were taken during the periods 2-20 September 1979 and 5-22 July 1980. The 1980 data set was used as an independent check on the relationships developed from the first data set. Additional verification data were collected from 8-26 May 1981.

\section{RESULTS AND DISCUSSION}

Using Bouguer's (Beer's) Law, the visible (PAR) direct beam radiation $\left(R_{\mathrm{DV}}\right)$ falling on a horizontal surface can be approximated by

$R_{\mathrm{DV}}=600 \exp \left[-0.185\left(P / P_{0}\right) \mathrm{m}\right] \cos \theta$

The $600\left(\mathrm{~W} \mathrm{~m}^{-2}\right)$ represents the average amount of visible (PAR) radiation available at the top of the atmosphere $(400-700 \mathrm{~nm})$. The solar constant, excluding the ultraviolet, was taken as $1320 \mathrm{~W} \mathrm{~m}^{-2}$, of which 0.45 is the fraction of radiation in the visible wave band (Moon, 1940). From the 1979 data, the ratio of visible to total solar radiation as a function of zenith angle (Fig. 1) indicates a near constant value of 0.46 for angles up to $80^{\circ}$.
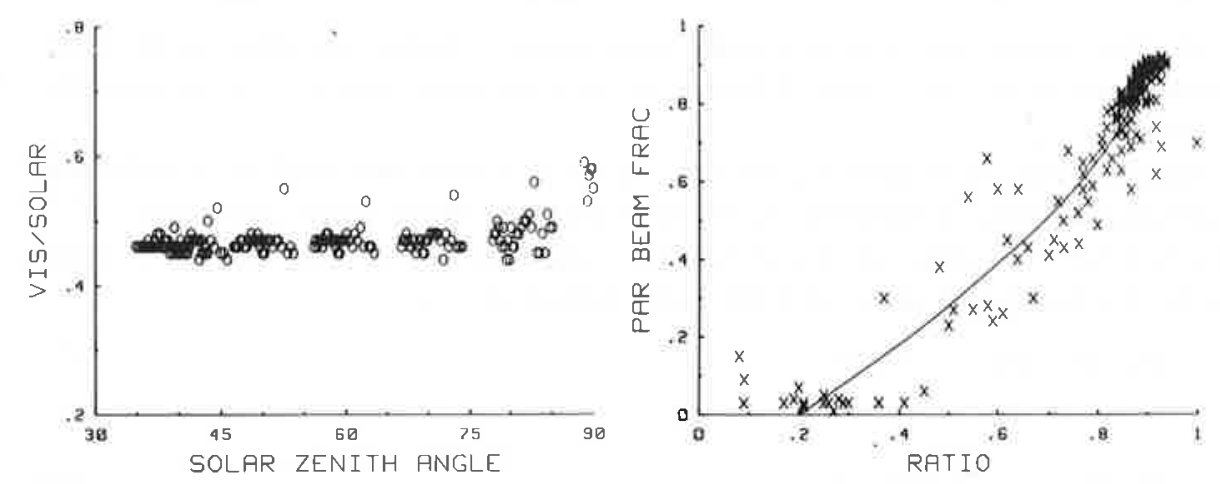

Fig. 1. The ratio of visible (PAR) to total solar radiation as a function of zenith angle for a range of sky conditions from the 1979 data set.

Fig. 2. The visible (PAR) beam divided by the total visible radiation, i.e., the beam fraction, as a function of RATIO (measured hourly total solar radiation divided by the calculated potential solar radiation) for a range of sky conditions from the 1979 data set. 
This ratio will be discussed in detail later. The extinction coefficient is $0.185, P / P_{0}$ the ratio of actual to sea level $(101.325 \mathrm{kPa})$ pressure, $m$ the optical air mass, and $\theta$ the zenith angle. The optical air mass was given by

$m=(\cos \theta)^{-1}$

Potential visible diffuse radiation $\left(R_{\mathrm{dV}}\right)$ was evaluated from

$R_{\mathrm{dV}}=0.4\left(600-R_{\mathrm{DV}}\right) \cos \theta$

where the term in parentheses represents the total available visible diffuse radiation. The 0.4 is the fraction of intercepted visible beam radiation that is converted to downward diffuse radiation at the surface. This value was determined by matching predicted, clear-sky diffuse radiation with the 1979 measurements.

The formulation for the potential near-infrared components of the solar spectrum take the same form as the visible components except that absorption by water vapor must be included in these calculations. The potential direct beam near-infrared radiation $\left(R_{\mathrm{DN}}\right)$ on a horizontal surface was calculated from

$R_{\mathrm{DN}}=\left[720 \exp \left(-0.06\left(P / P_{0}\right) m\right)-w\right] \cos \theta$

and the potential diffuse near-infrared radiation $\left(R_{\mathrm{dN}}\right)$ was evaluated as

$R_{\mathrm{dN}}=0.6\left[720-R_{\mathrm{DN}}-w\right] \cos \theta$

The $720\left(\mathrm{~W} \mathrm{~m}^{-2}\right)$ represents the near-infrared portion of the solar spectrum at the top of the atmosphere, the constant 0.6 was determined by matching predicted, clear-day diffuse radiation with the 1979 measurements, and $w$ is the water absorption in the near infrared for $10 \mathrm{~mm}$ of precipitable water (adapted from Wang, 1976).

$w=1320 \operatorname{antilog}_{10}\left[-1.1950+0.4459 \log _{10} m-0.0345\left(\log _{10} m\right)^{2}\right]$

Use of this equation assumes that precipitable water absorbs only nearinfrared radiation, and that $10 \mathrm{~mm}$ of precipitable water is a reasonable minimum.

Estimated values of total visible $\left(S_{\mathrm{V}}\right)$ (or total near-infrared, $\left.S_{\mathrm{N}}\right)$ radiation are obtained from a measurement of total incoming solar radiation $\left(R_{\mathrm{T}}\right)$ multiplied by the ratio of the potential total visible (or near-infrared) radiation to the potential value of total solar radiation, i.e.,

$S_{\mathrm{V}}=R_{\mathrm{T}}\left[R_{\mathrm{V}} /\left(R_{\mathrm{V}}+R_{\mathrm{N}}\right)\right]$

and

$S_{\mathrm{N}}=R_{\mathrm{T}}\left[R_{\mathrm{N}} /\left(R_{\mathrm{V}}+R_{\mathrm{N}}\right)\right]$

where

$R_{\mathrm{V}}=R_{\mathrm{DV}}+R_{\mathrm{dV}}$ 

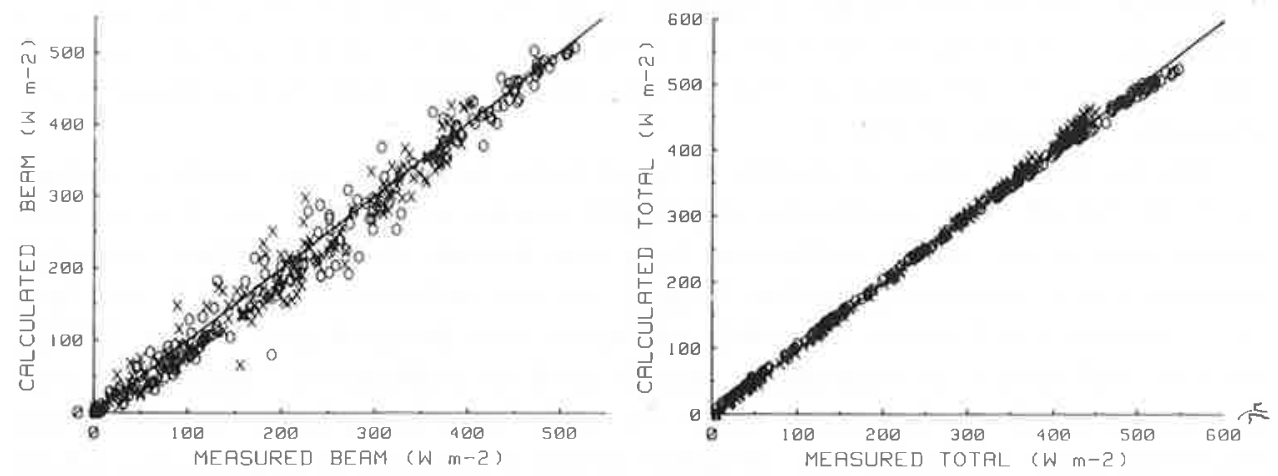

Fig. 3. Comparison of measured vs. calculated hourly values of the visible ( $x$ ) and NIR (o) beam components for the period 5-22 July, 1980. The slope, standard error of the estimate, and $r^{2}$ for the visible and NIR components are: $0.978,0.983 ; 24.5 \mathrm{~W} \mathrm{~m}^{-2}, 24.6 \mathrm{~W}$ $\mathrm{m}^{-2}$; and $0.963,0.976$; respectively.

Fig. 4. Comparison of measured vs. calculated hourly values of the total (direct and diffuse) visible (x) and NIR (o) components for the period 5-22 July 1980. The slope, standard error of the estimate, and $r^{2}$ for the visible and NIR components are: 1.015, $0.986 ; 6.86 \mathrm{~W} \mathrm{~m}^{-2}, 6.73 \mathrm{~W} \mathrm{~m}^{-2}$; and $0.997,0.986$; respectively.

and

$R_{\mathrm{N}}=R_{\mathrm{DN}}+R_{\mathrm{dN}}$

The fraction of the PAR (or NIR) in the direct beam was estimated from an analysis of the 1979 data for a range of sky conditions from clear to partly cloudly to overcast. The PAR beam fraction was given by

$f_{\mathrm{V}}=\frac{R_{\mathrm{DV}}}{R_{\mathrm{V}}}\left[1-\left(\frac{A-\mathrm{RATIO}}{B}\right)^{2 / 3}\right]$

while the fraction of NIR in the direct beam was given by

$f_{\mathrm{N}}=\frac{R_{\mathrm{DN}}}{R_{\mathrm{N}}}\left[1-\left(\frac{C-\mathrm{RATIO}}{D}\right)^{2 / 3}\right]$

where $A, B, C$, and $D$ were $0.9,0.7,0.88$, and 0.68 ; respectively. RATIO was defined as the ratio of measured to potential solar radiation, i.e., $R_{\mathrm{T}} /\left(R_{\mathrm{V}}+\right.$ $\left.R_{\mathrm{N}}\right)$. The constants in eq. 11 were evaluated by fitting a power equation to the 1979 measurements of PAR, direct-beam fraction and RATIO, Fig. 2. This was not a least-squares fit; rather, the coefficients were chosen to yield a good fit by eye. Equation 12 was developed in a similar manner. These fractions $\left(f_{\mathrm{V}}\right.$ and $\left.f_{\mathrm{N}}\right)$ are never permitted to be negative because RATIO is never allowed to exceed $A$ or $C$. If RATIO should exceed $A$ or $C$, it is set equal to $A$ or $C$. Data for zenith angles greater than $80^{\circ}$ were not used in this analysis. The fractions of diffuse radiation in the visible and nearinfrared were equal to one minus the respective direct beam fraction. 
Predictions of the beam components of the visible and the near-infrared using the independent data sets, which were taken under a wide range of sky conditions, are given in Fig. 3. The total visible and near-infrared components are shown in Fig. 4.

The measured ratio of visible to total solar radiation was nearly constant at 0.46 for all sky conditions and zenith angles up to $80^{\circ}$; see Fig. 1 . This measurement of visible radiation does not include the UV. Other reported values of this ratio may be due in part, to the inclusion of the UV, the lack of a standard definition of visible radiation (see Stanhill and Fuchs, 1977), or the difference in calibration scales used in calibration certificates (the International Pyrheliometric Scale of 1956 and the Fourth International Pyrheliometric Comparisons, October 1975). Pereira et al. (1982) also found the value for the ratio under clear sky conditions and zenith angles up to $70^{\circ}$ to be 0.46 . Meek et al. (1982) determined this ratio to be 0.45 regardless of cloud cover or day length. In a thorough analysis, Szeicz (1974) found this ratio to be 0.50 for conditions in Gt. Britain. Using data sets from different locations representing different integration periods, Stanhill and Fuchs (1977) found this ratio for elevation angles greater than $10^{\circ}$ to be 0.49 , 0.47 , and 0.49 for half hourly, daily, and monthly data, respectively. They concluded that, within experimental errors and lack of a standard definition, the ratio of visible to total solar radiation can be taken as 0.50 , a value in agreement with that of Szeicz. However, Britton and Dodd (1976) found this ratio to vary as a function of solar radiation flux density from a high of 0.58 at $0-5 \mathrm{MJ} \mathrm{m}^{-2} \mathrm{~d}^{-1}$ to a low of 0.47 at $25-30 \mathrm{MJ} \mathrm{m}^{-2} \mathrm{~d}^{-1}$. Stigter and Musabilha (1982) found in the tropics that this ratio takes on the value of 0.51 for clear sky conditions and 0.63 for cloudy conditions. It thus appears that recent measurements in the mid latitudes indicate a near constant value for this ratio, while further measurements are necessary in the tropics.

The relationship between total solar radiation as measured by the Eppley PSP and the LI-COR silicon cell pyranometer was excellent (Fig. 5). The method for determining diffuse radiation from the silicon cell pyranometer was not as straightforward as that for the total radiation. Correction for the effect of the shadowband on the diffuse measurement must be made (Drummond, 1964). This value of diffuse radiation must be corrected further for the distortion in the spectral response of the silicon cell pyranometer. Silicon cells tend to respond poorly in the blue region and peak in the near-infrared. Clear-sky diffuse radiation peaks in the blue part of the spectrum, whereas on a cloudy day the peak shifts to longer wavelengths. Therefore, any correction factor must account for the changing spectral composition of the diffuse light. A correction factor was derived from the two measurements of diffuse radiation (silicon cell and Eppley) Fig. 6, which, when multiplied by the shadowband-corrected value of diffuse radiation from the silicon cell pyranometer, yields an estimate of the actual diffuse radiation. This correction factor is 

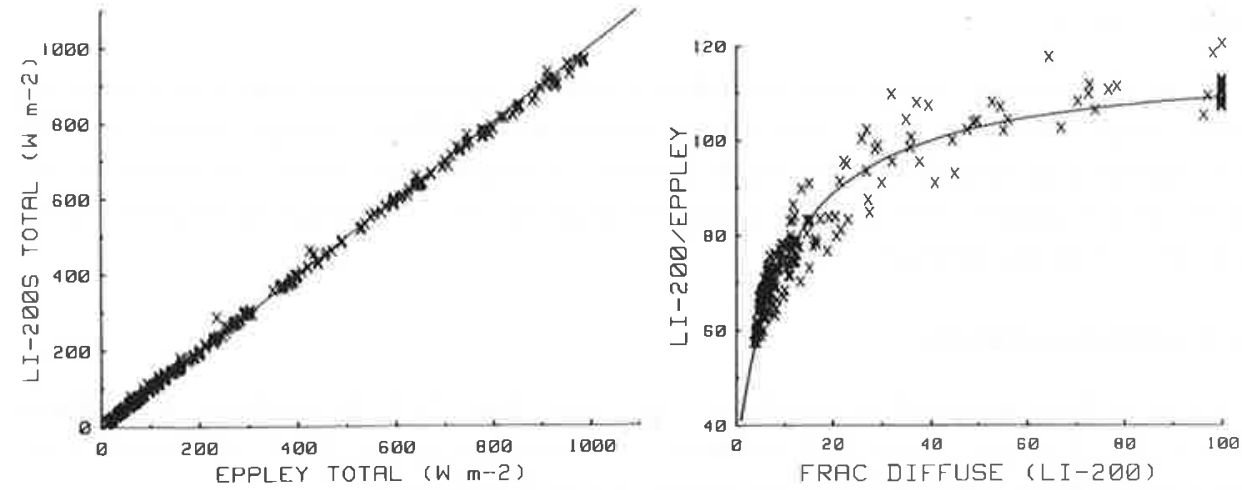

Fig. 5. Comparison of total solar radiation as measured by an Eppley PSP and a LI-COR silicon cell pyranometer for the period 8-26 May 1981. The slope, standard error of the estimate, and $r^{2}$ are $0.992,9.1 \mathrm{~W} \mathrm{~m}^{-2}$, and 0.98 , respectively.

Fig. 6. The ratio of the diffuse radiation as measured by a silicon cell (LI-200) and Eppley Black and White pyranometers as a function of the total diffuse divided by the total solar radiation measured by the silicon cell pyranometers. Values are in percentages.

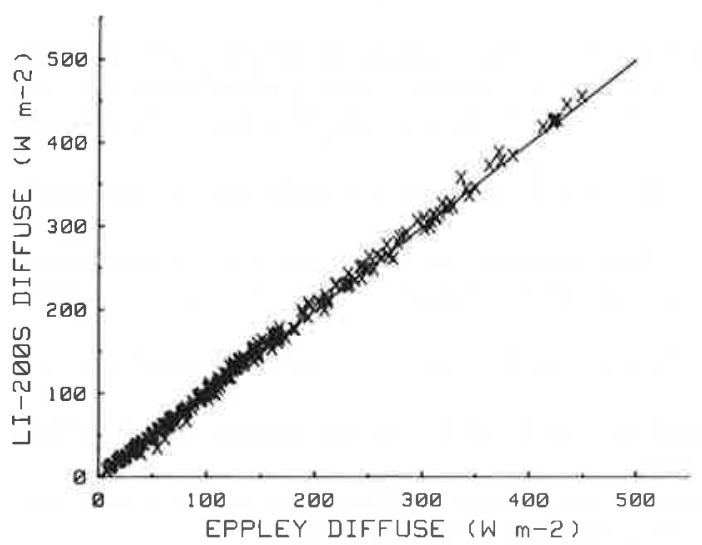

Fig. 7. Comparison of diffuse solar radiation as measured by an Eppley Black and White and LI-COR silicon cell pyranometer for the period 8-26 May 1981. The slope, standard error of the estimate, and $r^{2}$ are $1.014,5.2 \mathrm{~W} \mathrm{~m}^{-2}$, and 0.99 , respectively.

CORREC $=\left[1.17-\frac{1}{1.2+11.8 D R}\right]^{-1}$

where $D R$ is the ratio of the shadowband corrected value of diffuse radiation from the silicon cell to the measured total solar radiation. There is excellent agreement in measurements of diffuse radiation made with the two types of pyranometers (Fig. 7). 


\section{CONCLUSION}

A methodology has been developed from experimental data to partition total solar radiation into the direct beam and diffuse components of both the visible and near-infrared wave bands. A correction term has been developed which allows for the accurate measurement of diffuse radiation with a silicon cell pyranometer.

\section{ACKNOWLEDGMENTS}

Don Lukens assisted in the data collection. Drs. N.J. Rosenberg, B.L. Blad, and C.B. Tanner provided valuable comments from their different perspectives which clarified and strengthened this article.

\section{REFERENCES}

Britton, C.M. and Dodd, J.D., 1976. Relationships of photosynthetically active radiation and shortwave radiation. Agric. Meteorol., 17: 1-8.

Brock, T.D., 1981. Calculating solar radiation for ecological studies. Ecol. Model., 14: $1-19$.

Dave, J.V., 1981. Transfer of visible radiation in the atmosphere. Atmos. Environ., 15: $1805-1820$.

Davies, J.A. and Idso, S.B., 1979. Estimating the surface radiation balance and its components. (pp. 183-210.) In: B.J. Barfield and J.F. Gerber (Eds.), Modification of the Aerial Environment of Crops, American Society of Agricultural Engineers, St. Joseph, MI, $538 \mathrm{pp}$.

Drummond, A.J., 1964. Comments on "Sky radiation measurements and corrections". J. Appl. Meteorol., 3: 810-811.

Erbs, D.G., Klein, S.A. and Duffie, J.A., 1982. Estimation of the diffuse radiation fraction for hourly, daily, and monthly average global radiation. Sol. Energy, 28: 293302.

Gausman, H.W. and Allen, W.A., 1973. Optical parameters of leaves of 30 plant species. Plant Physiol., 52: 57-62.

Horowitz, J.L., 1969. An easily constructed shadow-band for separating direct and diffuse solar radiation. Sol. Energy, 12: 543-545.

Hubbard, K.G., Rosenberg, N.J. and Nielsen, D.C., 1983. Automated weather data network for agriculture. J. Water Resour. Plan. Manage., 109: 213-222.

Ideriah, F.J.K., 1981. A model for calculating direct and diffuse solar radiation. Sol. Energy, 26: 447-452.

Kondratyev, K. Ya., 1969. Radiation in the Atmosphere. Academic Press, New York, $912 \mathrm{pp}$.

Meek, D.W., Hatfield, J.L. and Howell, T.A., 1982. A generalized relationship between photosynthetically active radiation and solar radiation. Agron. Abstracts, 28 November-3 December 1982, Anaheim, CA. American Society of Agronomy, Madison, WI, p. 16.

Moon, P., 1940. Proposed standard solar radiation curves for engineering use. J. Franklin Inst., 230: 583-618.

Munro, D.S. and Young, G.J., 1982. An operational net shortwave radiation model for glacier basins. Water Resour. Res., 18: 220-230.

Norman, J.M., 1979. Modeling the complete crop canopy. (pp. 249-280.) In: B.J. Barfield and J.F. Gerber (Eds.), Modification of the Aerial Environment of Crops, American Society of Agricultural Engineers, St. Joseph, MI, 538 pp. 
Norman, J.M., 1980. Interfacing leaf and canopy light interception models. (pp. 49-67.) In: J.D. Hesketh and J.W. Jones (Eds.), Predicting Photosynthesis for Ecosystem Models, Vol. II, CRC Press, Boca Raton, FL, 304 pp.

Pereira, A.R., Machado, E.C. and de Camargo, M.B.P., 1982. Solar radiation regime in three cassava (Manihot esculenta Crantz) canopies. Agric. Meteorol., 26: 1-10.

Stanhill, G. and Fuchs, M., 1977. The relative flux density of photosynthetically active radiation. J. Appl. Ecol., 14: 317-322.

Stigter, C.J. and Musabilha, V.M.M., 1982. The conservative ratio of photosynthetically active to total radiation in the tropics. J. Appl. Ecol., 19: 853-858.

Szeicz, G., 1974. Solar radiation for plant growth. J. Appl. Ecol., 11: 617-636.

Wang, W.C., 1976. A parameterization for the absorption of solar radiation by water vapor in the earth's atmosphere. J. Appl. Meteorol., 15: 21-27. 